\title{
Application of thermogrammetry in panel heating and cooling systems
}

\author{
by Birol I. Kilkis*
}

*WattsRadiant, Springfield, Missouri, USA

\begin{abstract}
Simultaneous energy saving and comfort advantages of radiant panels are especially important in green buildings using Hybrid HVAC systems. However, introduction of forced-air convective systems complicates the performance calculations. In this study an analytical algorithm was developed to accurately calculate the radiant panel heat flux using thermogrammetry. This algorithm calculates the actual heat flux on the panel surface and the efficiency. The same technique can also be used to detect leaks in hydronic panels or hot spots in electric panels before the failure occurs or compounds.
\end{abstract}

\section{Introduction}

With the depleting nature of fossil fuels and their increasing costs, lowenthalpy, waste, and alternative energy resources are becoming feasible alternatives for space heating and cooling. Despite several exergetic and environmental benefits of utilizing low-enthalpy energy resources mentioned by Rosen and Dincer [1], technical difficulties arise due to the mismatch between the supply and demand side temperatures, when a conventional space heating and cooling system is used [2]. Performance of today's heating and cooling equipment are highly sensitive and demandful on the operating temperature of the heat transfer fluid used, where lowenthalpy and low-intensity energy systems provide moderate fluid temperatures and moderate intensity power. Radiant panels either hydronic or electric as shown in figure 1 and figure 2 respectively can directly couple with low-enthalpy energy resources. However radiant panels cannot handle latent loads. This necessitates the introduction of latent systems into the same conditioned space like forced-air convection systems. A so-called Hybrid HVAC System coupled to a wind turbine, heat pump, and or heat pipes is shown in figure 3 [4]. However, the introduction of forced-convection to the system complicates the heat flux calculations and predictions on panel surfaces, because all existing data in the literature correspond to radiation and natural convection heat transfer taking place from (to in cooling) radiant panel surfaces. This study aims to generate a reliable engineering data base for hybrid HVAC panel under actual operating conditions using thermogrammetry. Either electric or hydronic, the heat transfer elements like hydronic tubes or electric cables show up on the panel surface in hot (or cold in cooling) patterns as shown in the inset of figure 3 . The temperature variation depends on the magnitude of the heat flux, presence of forced-air in the vicinity of the panel surface, indoor surface temperatures, panel construction, the type of panel covering, and to a certain extent the heat losses (gains in cooling) from panels. 


\section{Heat flux on the radiant panel surface}

The overall heat flux, a combination of radiant and convective heat transfer can be expressed by a single equation:

$$
q=c\left(T_{p}-T_{a}\right)^{n}
$$

Here $q$ is the overall surface heat flux in $\mathrm{W} / \mathrm{m}^{2} . T_{p}$ is the effective panel surface temperature, $T_{a}$ is the dry-bulb average indoor air temperature. $c$ and $n$ are empirical correlation coefficients depending upon the location of the panel (wall, floor, or ceiling). These coefficients are known for a radiant panel system, when used alone in the conditioned indoor space. However these data are not valid when forced-air convective system is introduced to the same indoor space in a Hybrid HVAC System. Such data, which should modify $c$ and $n$ does not exist in the literature:

$$
q=c^{\prime}\left(T_{p}-T_{a}\right)^{n^{\prime}}
$$

With the recent advances of thermogrammetry and improved precision and accuracy of thermal cameras, now it is technically feasible to calculate the effective surface temperature and calculate panel surface heat flux under any conditions, including Hybrid HVAC Systems. However it is first necessary to calibrate the camera for test conditions in the given indoor space using a color-heat calibration panel as shown in figure 4 . This is a small size, $0.25 \mathrm{~m} \times 0.25 \mathrm{~m}$ electric panel with an identical construction with the actual panel. This panel is first laid in the indoor space on the floor, wall, or ceiling to be tested. For heating mode calibration electric resistance cables embedded in the panel are used to calibrate with at least five controlled heat fluxes, measured by the electric power used. The calibration panel is heavily insulated at the back and edges so that electric power $/ 0.25 \mathrm{~m}^{2}$ can be directly correlated to the surface heat flux $q_{c a l}$ on the calibration panel. In cooling mode thermo-electric effect may be employed, because usually the cooling panel surface temperature is within $10^{\circ} \mathrm{C}$ or less with the indoor air temperature to avoid surface condensation. In this case however the calibration panel itself needs to be calibrated for the thermo-electric effect. Due to the small size of the calibration panel, $q_{\text {cal }}$ values need to be adjusted before embedding to equation 2 :

$q=q_{c a l}\left(\frac{0.25}{D_{p}}\right)^{s}$

Here $s$ is 0.08 for ceiling heating and floor cooling, 0.25 for ceiling heating and floor cooling, and 0.113 for wall heating and cooling. $D_{p}$ is the equivalent diameter ( $4 \times$ surface area/perimeter of the panel). During color-heat calibration, the panel surface temperature $T_{p}$ is recorded while the thermal camera scans the calibration panel surface. By using the above-mentioned at least five different data points and the consumed electrical power or thermo-electric effect power (for cooling) $c^{\prime}$ and $n$ ' are determined using the algorithm given in BSR/ASHRAE Standard 138P, with primary contribution of Kilkis [4]. This procedure is repeated for at least five 
different locations in the indoor space $c^{\prime}$ and $n$ ' are averaged. This steps conclude the calibration process, such that a direct relationship between the thermal image, $T_{p}$, and $q$ (through equation 2 has been established. Now the thermal camera is ready to test and generate data for the actual panel in the same indoor space.

\section{Calculation of the panel surface heat flux and panel efficiency}

The thermal camera is precisely traversed on the indoor floor on a thermally and hydrodynamically non-invasive light trolley. For floor panels the camera is pointed vertically down at about $1.5 \mathrm{~m}$ above the floor. For ceiling panels, the camera points vertically up, and for wall panels, the camera looks horizontally sidewise. While precisely recording the $x, y$ co-ordinates of the camera position, thermal images and the corresponding panel surface temperatures $T_{p i}$ are recorded in a precise grid pattern shown in figure 5. For each measured $T_{p i}$ equation 2 gives $q_{i}$ at the measured indoor air temperature at position $x_{i}, y_{i}$ Then using equation 4 , the overall actual panel surface heat flux is calculated. From the measured delivered or extracted heat (in cooling) to (from) the panel through the hydronic or electrical circuit the thermal efficiency can be calculated from equation 5 .

$$
q=\frac{\sum_{i=1}^{p} \sum_{j=1}^{r}\left(y_{i+1}-y_{i}\right)\left(x_{i+1}-x_{i}\right) c^{\prime}\left(T_{p i}-T_{a}\right)^{n}}{\sum_{i=1}^{p} \Sigma_{j=1}^{r}\left(y_{i+1}-y_{i}\right)\left(x_{i+1}-x_{i}\right)}
$$

Here the numerator is the incremental heat transfer rate at each individual panel grid and the denominator is the total panel area $A_{p}\left(\mathrm{~m}^{2}\right) . p$ and $r$ are the grid numbers in $x$ and $y$ directions.

$$
X=\frac{q A_{p}}{Q}
$$

Here $Q$ is the delivered or extracted heat to the panel, measured at the hydronic or electrical system of the panel. $X$ is the efficiency of the panel. $(1-X)$ is a measure of the back and edge heat losses (gains in cooling) of the panel.

\section{REFERENCES}

[1] Rosen, M. A. and Dincer, M. Energy and exergy analyses of sectoral energy utilization: an application for Turkey," $1^{\text {st }}$ Int. Trabzon Energy and Environment Symposium Proceedings, Vol. 3, pp. 1059-1065 (1996).

[2] Kilkis, I. B. An analytical optimization algorithm for wind energy coupled GSHP systems for sustainable building HVAC. 2003 ASME Int. Mechanical Engineering Congress and Exposition Proceeding, Washington DC, November 16-21 (2003)

[3] Kilkis.I. B. A heat pipe coupled composite radiant wall panel hybrid HVAC system. ASME International Mechanical Engineering Congress, IMECE 2004, paper accepted, Anaheim (2004)

[4] BSR/ASHRAE Standard 138P. Method of Testing for Rating Ceiling Panels for Sensible Heating and Cooling. Publication Draft. ASHRAE: Atlanta (2004) 
http://dx.doi.org/10.21611/qirt.2004.001

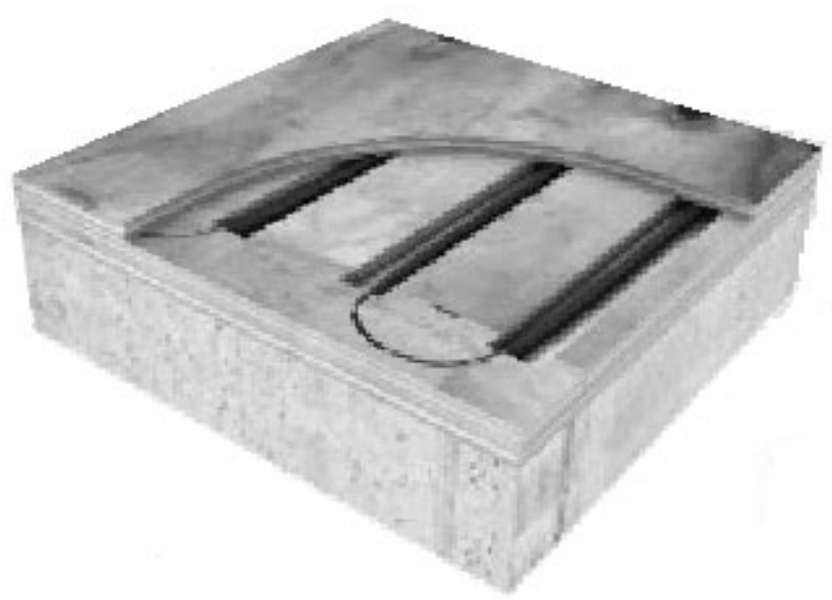

Fig. 1. A typical hydronic floor heating panel)

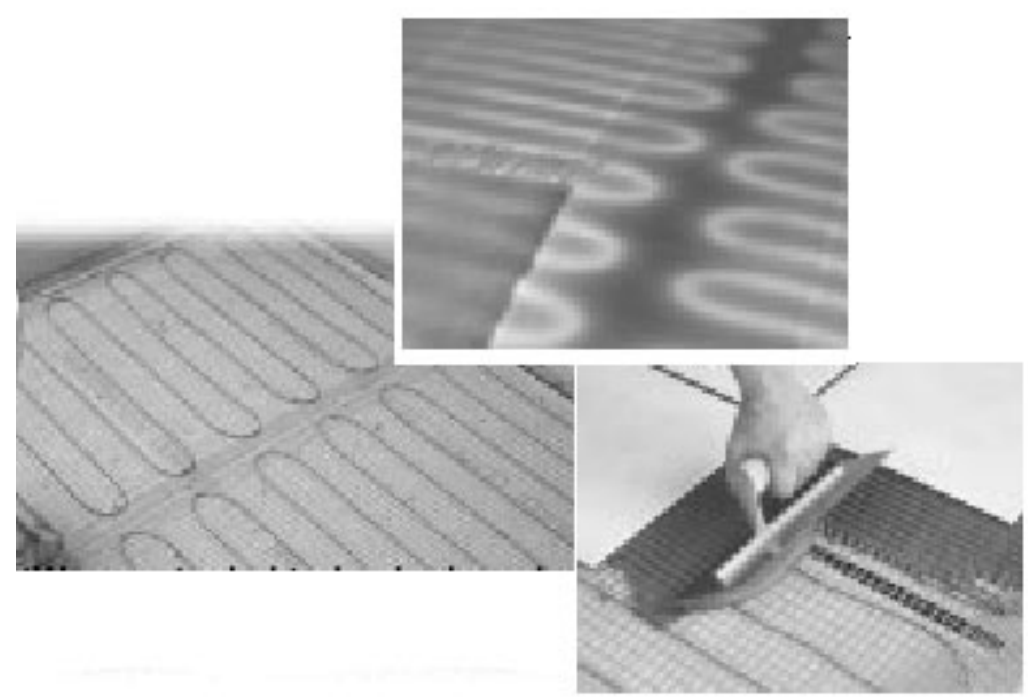

Fig. 2. A typical floor heating electric mat and thermo graphic image 
http://dx.doi.org/10.21611/qirt.2004.001

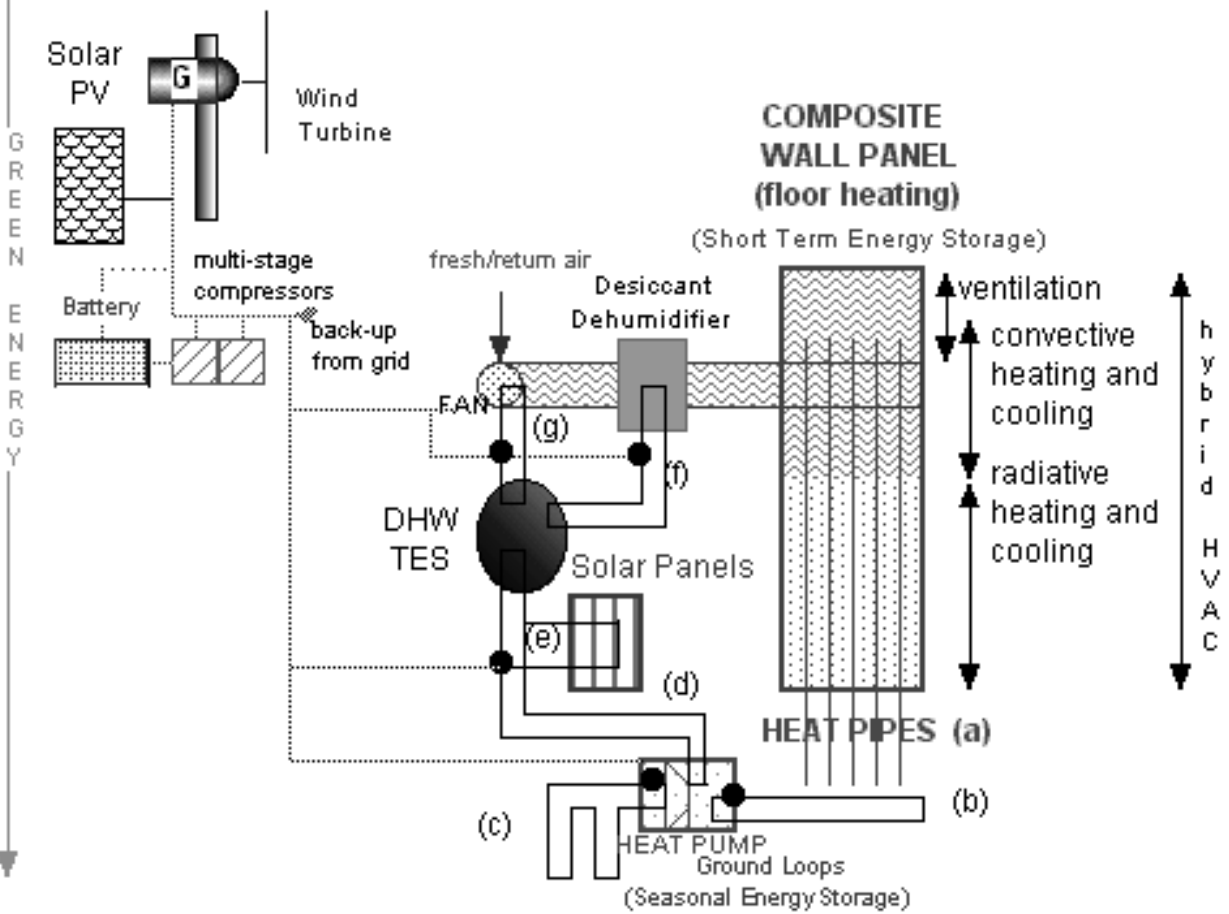

Fig. 3. Wind driven ground source heat pump operated hybrid HVAC systems with composite wall panel and heat pipes [3]

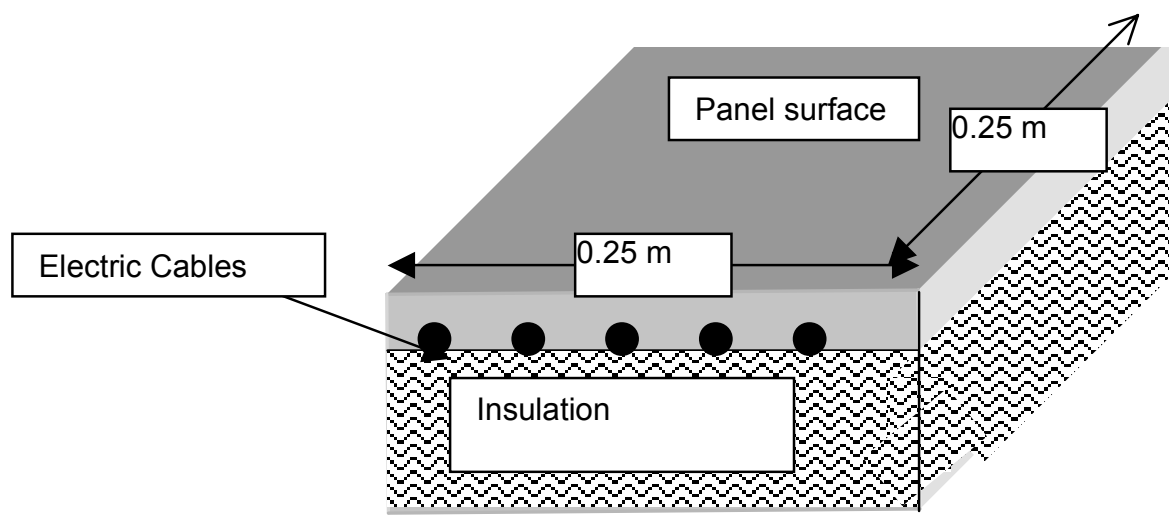

Fig. 4. Color-Heat Output calibration panel 
http://dx.doi.org/10.21611/qirt.2004.001

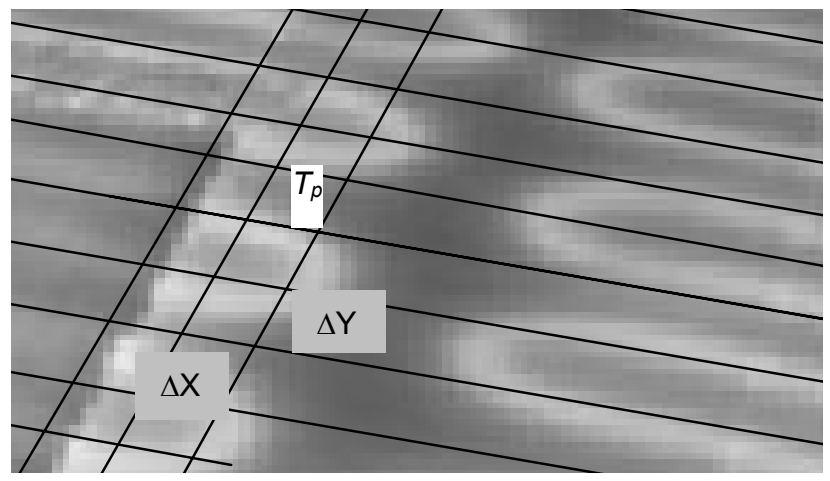

Fig. 5. Grid system for thermographic recordings 